\title{
Psychological factors contributing to parenting styles: A
}

\section{systematic review [version 1; peer review: 1 approved with}

\section{reservations, 1 not approved]}

\section{Zahra Vafaeenejad'1, Fourozan Elyasi², Mahmood Moosazadeh³, Zohreh Shahhosseini (iD 4}

\footnotetext{
${ }^{1}$ Student Research Committee, Mazandaran University of Medical Sciences, Sari, Iran 2Psychiatry and Behavioral Sciences Research Center, Addiction Institute, Mazandaran University of Medical Sciences, Sari, Iran ${ }^{3}$ Health Sciences Research center, Addiction Institute, Mazandaran University of Medical Sciences, Sari, Iran

${ }^{4}$ Sexual and Reproductive Health Research Center, Traditional and Complementary Medicine Research Center, Addiction Institute, Mazandaran University of Medical Sciences, Sari, Iran
}

V1 First published: 25 Jun 2018, 7:906

https://doi.org/10.12688/f1000research.14978.1

Latest published: 09 Apr 2019, 7:906

https://doi.org/10.12688/f1000research.14978.2

\section{Abstract}

Background: The set of strategies used by parents to put their children's behaviors under control are called parenting styles, which can be influenced by numerous factors including socio-economic variables, cultural differences, personal characteristics, and psychological factors. These factors can differently contribute to parenting style. Thus, the purpose of this systematic review was to examine psychological factors affecting parenting style.

Methods: This study was a comprehensive literature review using the keywords of parenting styles, psychological factors, and parenting to search the databases of Google Scholar, PubMed, Scopus, Web of Science, and Scientific Information Database. In this respect, 416 articles were extracted. 368 articles were removed after reviewing their abstracts and full text and eventually 48 articles were selected to elicit the required data.

Results: Our findings were classified under two categories: factors related to parents (mental health status, self-efficacy, parenting stress, perfectionism, personality traits, childhood trauma, marital satisfaction, parents' attachment style, perceived parenting style, and substance abuse); and those related to children (child developmental and mental disability, child temperament, and anxiety).

Conclusions: Considering the multiple psychological factors that affect parenting style, it is recommended to include an assessment of parent-child psychological status in family health programs in order to identify the needs for health-oriented care and take steps towards the development of parenting skills.

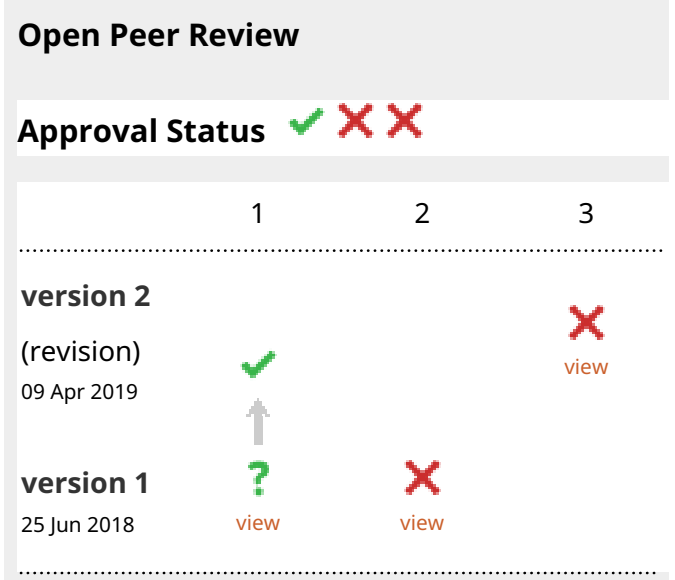

1. Maryam Zamanian, Arak University of Medical Sciences, Arak, Iran

2. Weiqiao Fan, Shanghai Normal University, Shanghai, China

3. Luísa Barros (iD), University of Lisbon,

Lisbon, Portugal

Any reports and responses or comments on the article can be found at the end of the article. 
Keywords

Parenting Styles, Psychological Factors, Parenting

\section{Corresponding author: Zohreh Shahhosseini (zshahhosseini@yahoo.com)}

Author roles: Vafaeenejad Z: Conceptualization, Data Curation, Investigation, Writing - Original Draft Preparation; Elyasi F: Conceptualization, Writing - Review \& Editing; Moosazadeh M: Investigation, Writing - Review \& Editing; Shahhosseini Z: Conceptualization, Supervision, Validation, Visualization, Writing - Review \& Editing

Competing interests: No competing interests were disclosed.

Grant information: Student Research Committee of Mazandaran University of Medical Sciences for their financial support of this project (code number, 2952).

The funders had no role in study design, data collection and analysis, decision to publish, or preparation of the manuscript.

Copyright: ( 2018 Vafaeenejad Z et al. This is an open access article distributed under the terms of the Creative Commons Attribution License, which permits unrestricted use, distribution, and reproduction in any medium, provided the original work is properly cited.

How to cite this article: Vafaeenejad Z, Elyasi F, Moosazadeh M and Shahhosseini Z. Psychological factors contributing to parenting styles: A systematic review [version 1; peer review: 1 approved with reservations, 1 not approved] F1000Research 2018, 7:906 https://doi.org/10.12688/f1000research.14978.1

First published: 25 Jun 2018, 7:906 https://doi.org/10.12688/f1000research.14978.1 


\section{Introduction}

Parenting styles refer to the set of strategies adopted by parents to control the behaviors of their children ${ }^{1}$. It has two models: positive parenting styles, i.e. authoritative parenting style; and negative parenting styles that are authoritarian, permissive, and neglectful ${ }^{2,3}$. In this respect, positive parenting styles are accompanied by encouraging outcomes for children such as optimism, self-esteem, and social-emotional development ${ }^{4-6}$, while negative parenting can lead to emotional disorders, behavioral problems ${ }^{7}$, aggression $^{8}$, as well as child anxiety ${ }^{9}$. Although, previous review studies have investigated different factors contributing to raising children and child maltreatment, including socio economic factors ${ }^{8,10}$, and parent and child characteristics $^{8,11-16}$, less is known about psychological factors that contribute to parenting style. The objective of this systematic review was to conduct a comprehensive literature review on the psychological factors affecting parenting styles.

\section{Methods}

In this review, the Preferred Reporting Items for Systematic Reviews and Meta-Analyses (PRISMA) statement was used as a guideline ${ }^{17}$. See Supplementary File 1 for the PRISMA checklist.

\section{Identification of the research question}

Considering the "P" component of PICO (Population of interest, intervention, control, outcome) criteria and FINER (Feasibility, Interesting, Novel, Ethical, Relevant) criteria, the research question was developed as below: ${ }^{18,19}$.

What are the psychological factors contributing to parenting styles?

\section{Search strategy}

According to the research question in this study, a search was carried out in the databases of Google Scholar, PubMed, Scopus, Web of Science, and Scientific Information Database (a Persian database). In this regard, the required articles were retrieved based on the use of medical subject headings, text words, and related keywords. The search strategy was as follows:

("Psychosocial Factors" OR Factors OR Determination OR Psychology) AND ("Child Rearing OR Child Rearing Styles" OR Parenting OR "Parent-Child Relations OR Parent-Child Relationship" OR "Parenting Styles”).

Eligibility criteria. All indexed and non-indexed original cross-sectional, longitudinal or review studies, in English or Persian, that meet the inclusion criteria, addressed the research question, reported parenting styles in at least one of the parents were retrieved, irrespective of the types of parenting style, recruitment method and instruments used for the assessment of parenting style. Studies that reported on the results of clinical trials were excluded from our review. 416 articles published within February 1984 and April 2017 were extracted. The search time lasted for four weeks between January 23rd and February 23rd in 2018.

Study selection. After removing duplicate articles (191), those remaining were examined in two stages. Firstly, the titles and a summary of all the remaining articles were independently reviewed by two authors ( $\mathrm{ZS}$ and $\mathrm{ZV}$ ). At this stage, 120 articles were excluded from the study.

Secondly, the full texts of all the remaining articles were examined and the items not referring to psychological factors in spite of attention to the factors related to parenting styles were excluded. Additionally, the reference lists of the selected articles were reviewed for more articles. Finally, 48 articles were used. Figure 1 illustrates the study flow.

\section{Summarization, extraction, and data reporting}

Two authors ( $\mathrm{ZH}$ and $\mathrm{ZV}$ ) independently extracted basic study information (author's name, title and year of publication, sample characteristics, type of study and outcomes such as: parenting styles, parent's behavior, parent child interaction, family interaction) for all included papers using a predefined evidence table shell. Third author (FE) reviewed the evidence tables for accuracy and completeness. The final evidence table is presented in Table 1. After selecting the final articles, the researchers carefully examined all the relevant articles, extracted the data, and then organized the information needed for the present study. The results of the literature review led to categorization of the contents on psychological factors contributing to parenting styles into several categories as presented in the Results section.

\section{Risk of bias}

Critical appraisal checklists were used to evaluate the quality of the studies. Checklists were adapted from the NewcastleOttawa quality assessment scale ${ }^{20}$ to assess three broad perspective of each study: the selection of the study groups, the comparability of the groups, and the ascertainment of either the exposure for case-control studies or the outcome of interest for cohort studies and cross-sectional studies. This checklist includes 8 questions for case control studies and cohort studies with maximum 9 score. For cross-sectional studies, this checklist includes 6 questions with maximum 7 score. Ottawa quality assessment scale has established content validity and inter-rater reliability ${ }^{21,22}$. We used The HE QAT to assess the methodological quality of all included reviews as well. The HE QAT assesses 10 criteria to measure the extent to which the methodological approach of a review guarded against bias with maximum 10 score $^{23}$. In this review, studies that received $\geq 5$ score from Newcastle-Ottawa scale and The HE QAT were included $^{20,23}$.

\section{Ethical considerations}

The authors assumed ethical considerations and general standards of publication including avoidance of plagiarism as well as multiple and simultaneous submissions and respect for the intellectual property rights of studies.

\section{Results}

The quality assessment of all studies presented in Table 1 is included in Supplementary File 2. The review of the literature led to the categorization of psychological factors affecting parenting styles as factors related to parents and those to children.

A summary of included studies are presented in Table 1. 


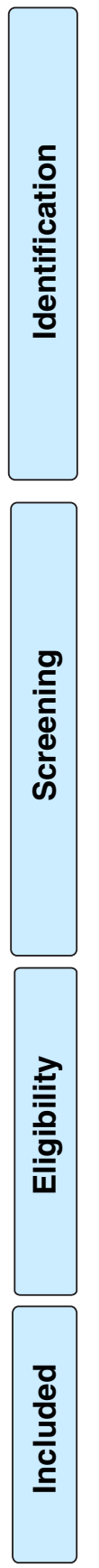

\section{Articles identified through search in the} databases $(n=416)$

Google Scholar $(n=242)$

PubMed (including Medline) $(n=52)$

Scopus $(n=50)$

$\operatorname{SID}(n=30)$

Web of science $(n=42)$
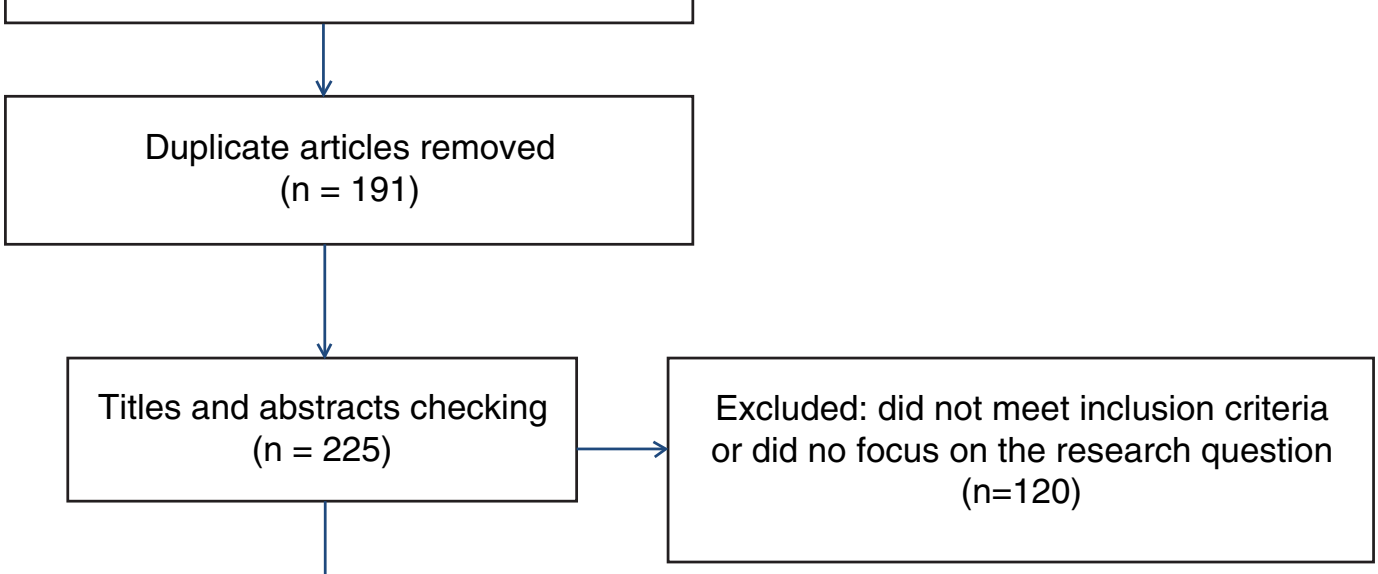

Figure 1. Study flow diagram.

Psychological characteristics relating to parents

Mental health status. Parents' mental health status is often directly correlated with parenting styles. As can be seen, parents affected with psychological distress may treat their own children with hostility and rejection. Such parents may adopt harsh disciplinary rules and probably make use of physical punishment $^{10,24}$. In this regard, it has been shown that a history of major depressive disorders is inversely correlated with authoritative parenting styles and it is positively correlated with authoritarian parenting style ${ }^{24}$. Moreover, depressed parents do not show proper sentiments or emotions towards their children or their feelings about parenting responsibilities are assumed negative ${ }^{25}$. These parents may have low self-esteem, reduced self-efficacy, negative emotions, more anger and distress, as well as negative worthlessness to themselves or negative attitudes towards their parenting abilities ${ }^{11,26,27}$, which have an impact on the trust between parents and children ${ }^{12,28,29}$. On the other hand, mothers suffering from bipolar disorder are likely to 


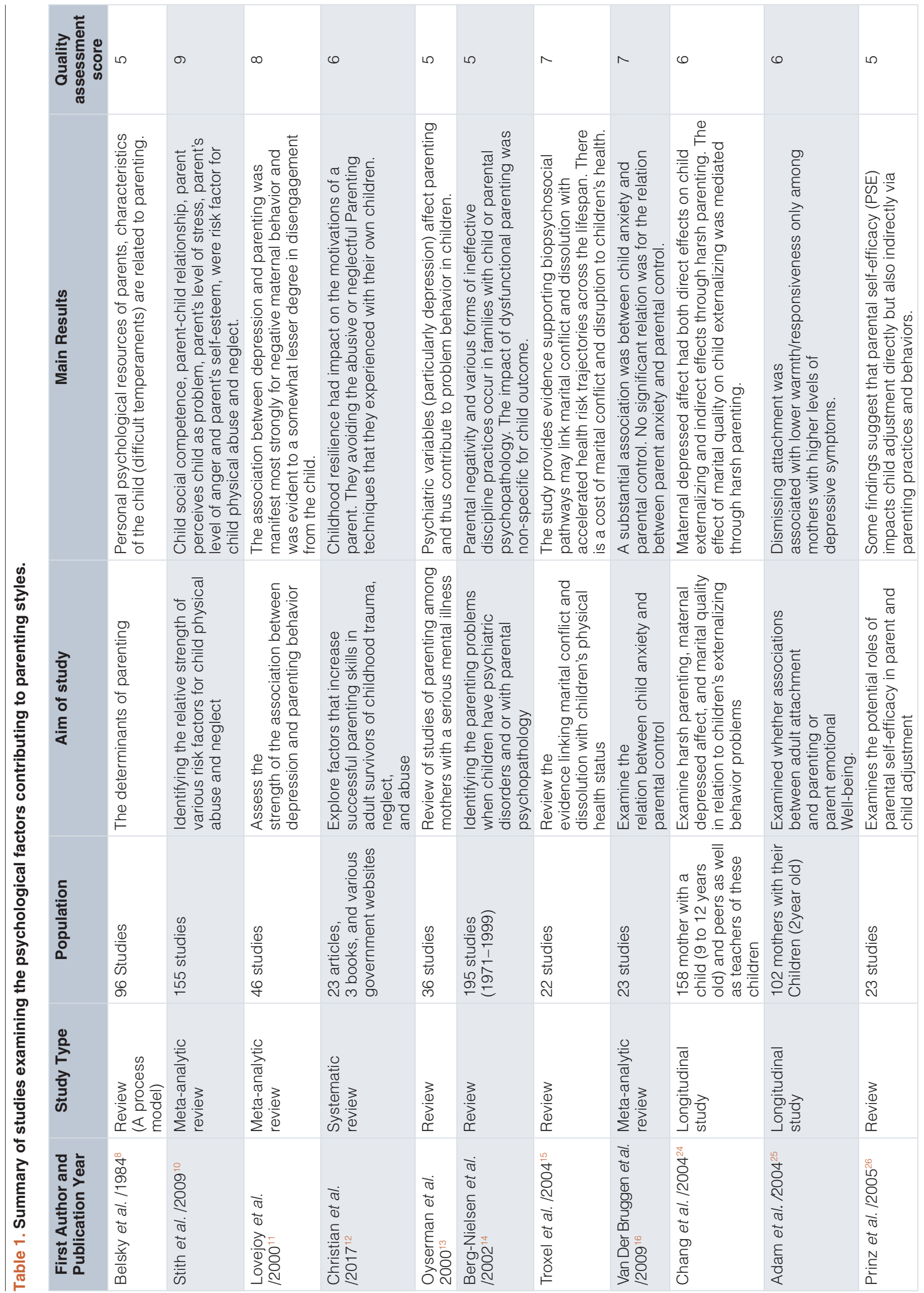




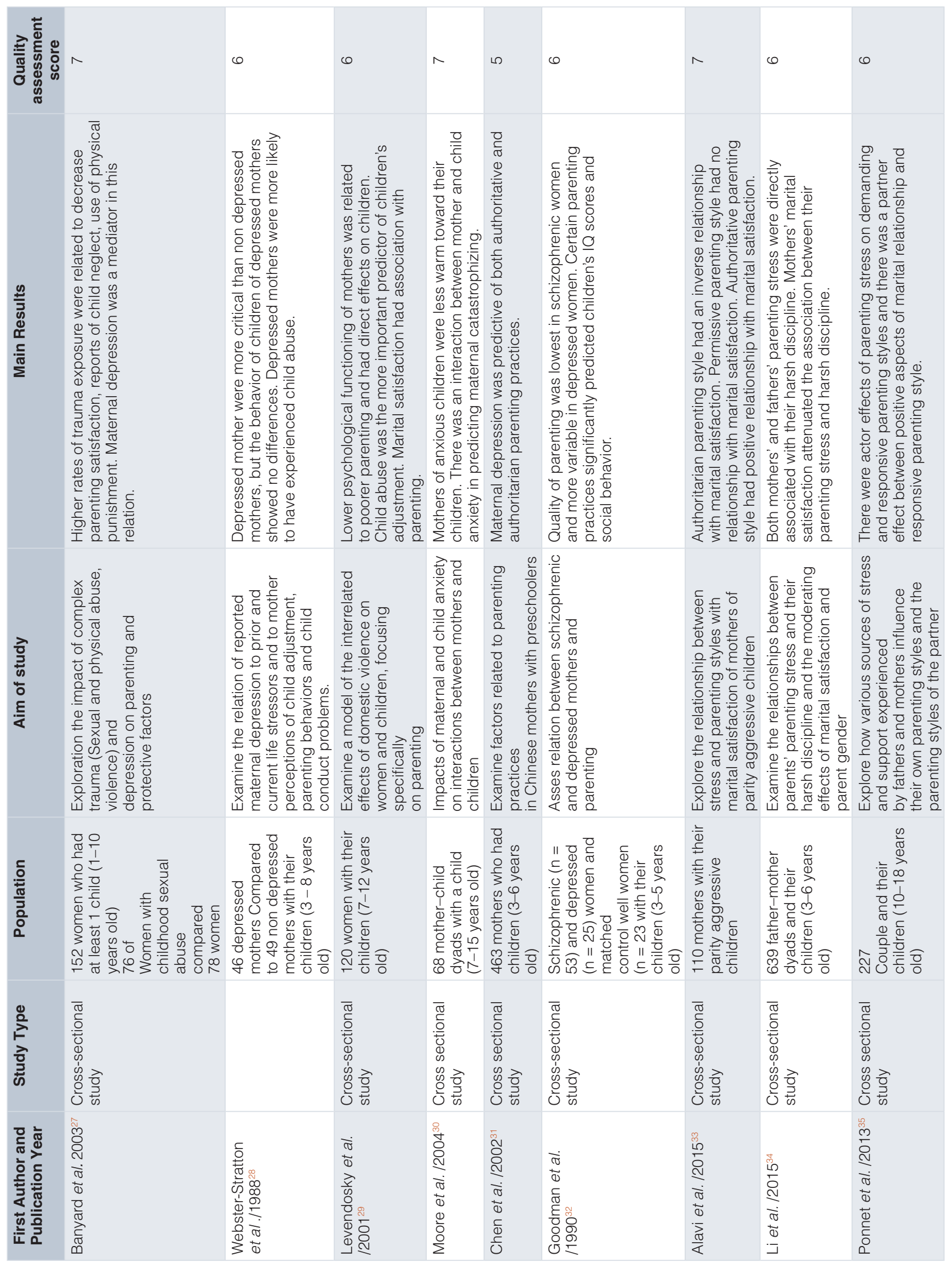




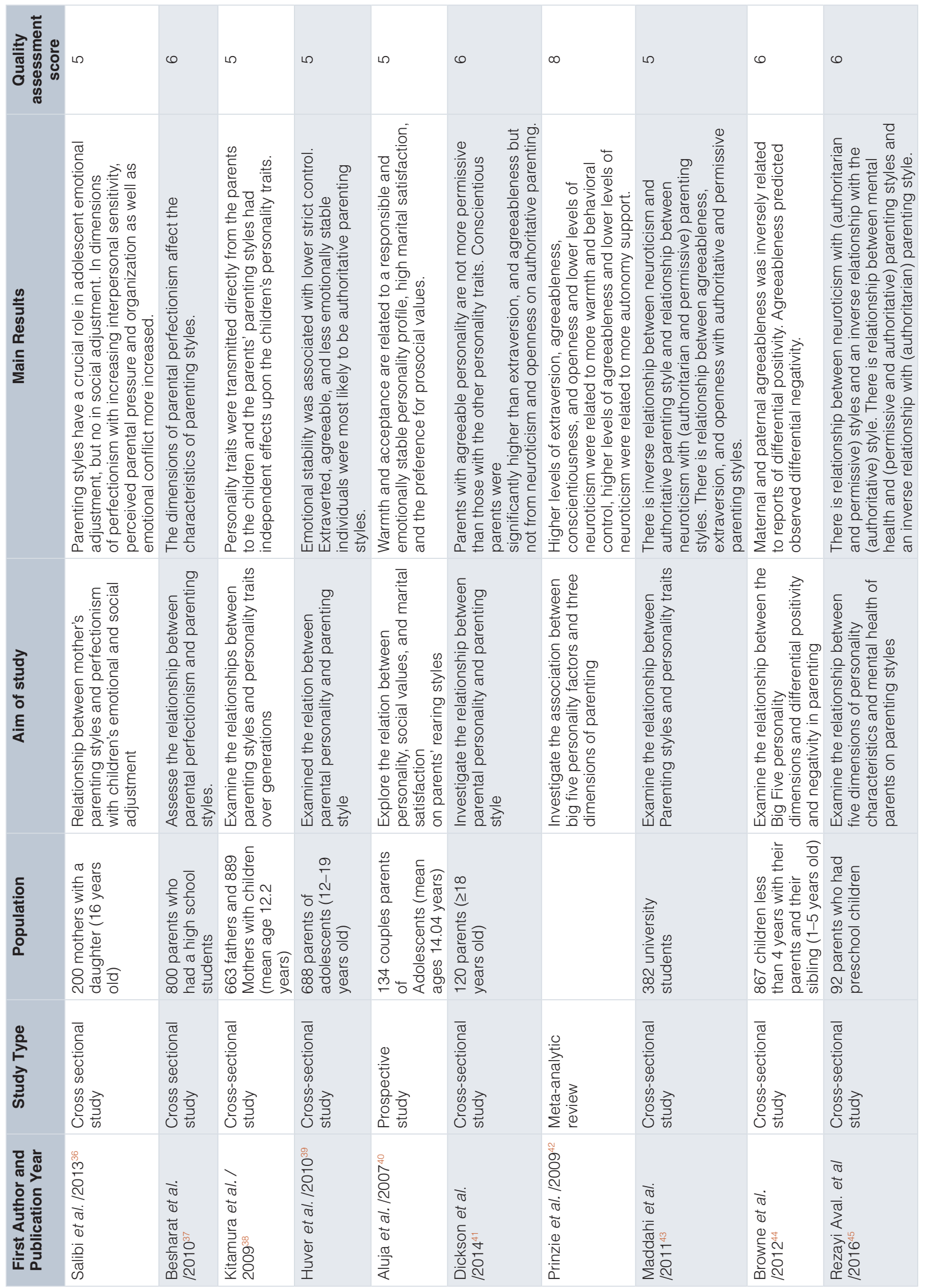




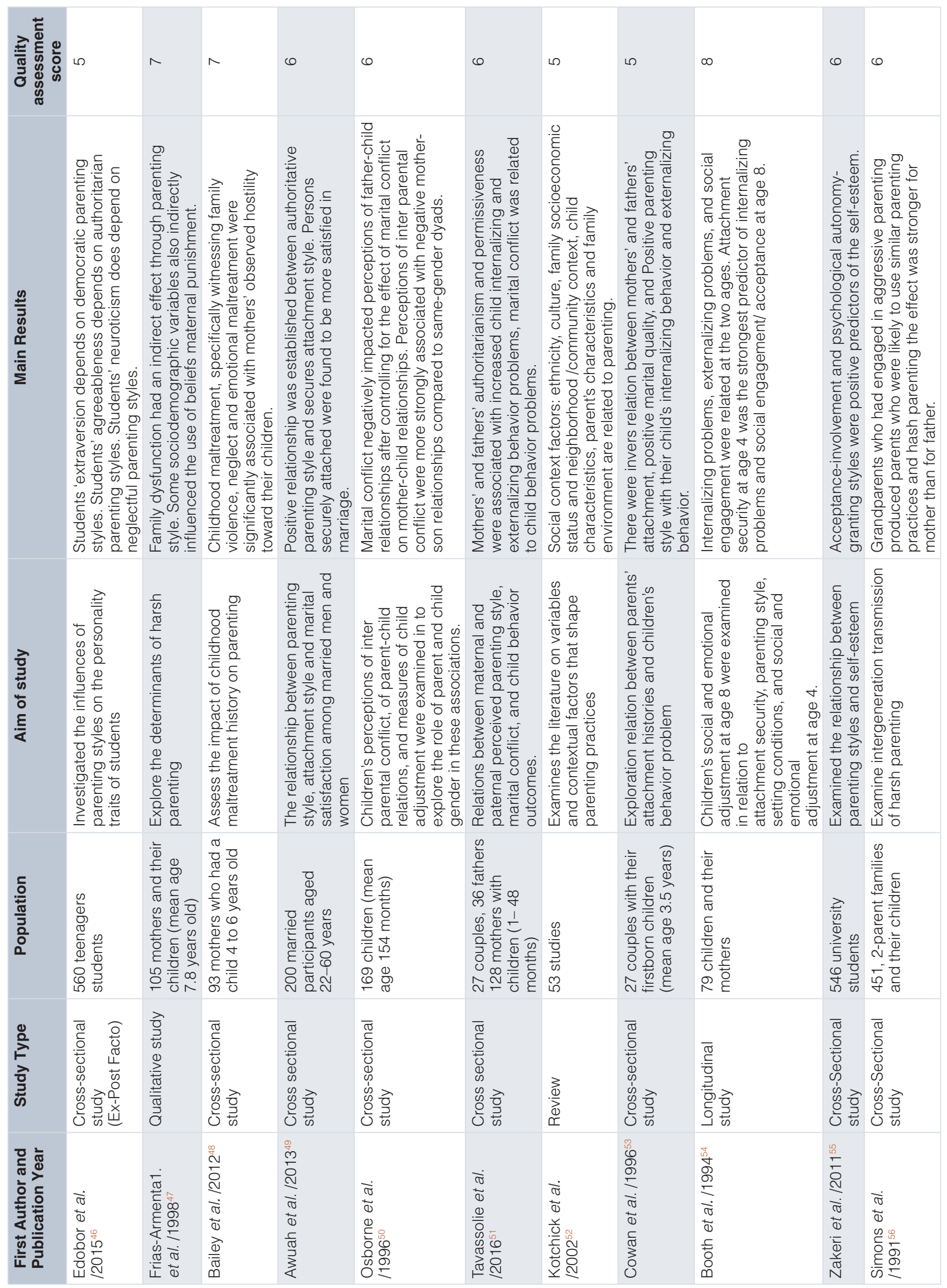




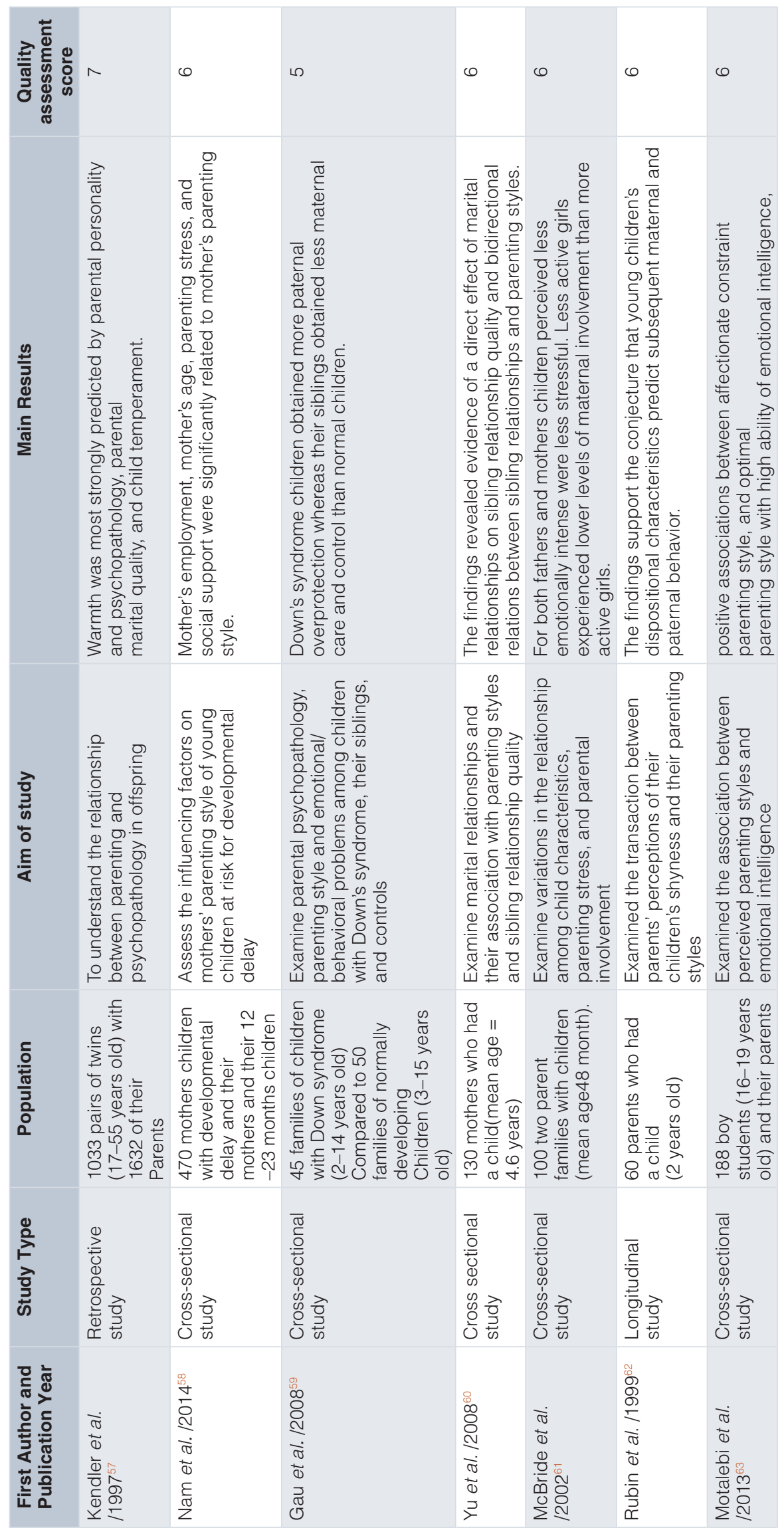


adopt an avoidant and insecure attachment style towards their children and show more anger in their interactions with family members ${ }^{13}$. Anxiety can be also a stressor with undesirable effects on a healthy coping system and parents' compliance problems and finally create negative parenting. Such parents may use harassment of their children as a first choice of parenting ${ }^{12}$, or parents' interactions with children and their parenting may be accompanied by excessive control and rejection $^{30,31}$.

One of the serious problems in the domain of parents' mental health affecting parenting can be schizophrenia. In this regard, it has been shown that children that have schizophrenic parents grow up with many environmental stressors, such as parental dysfunction. Schizophrenia also has a significant effect on the ability to maintain a close and reciprocal relationship and this issue has an impact on parenting capacity. It has been observed that mothers of schizophrenic women are more remote, insensitive and it is likely to be correlated with less parenting skills ${ }^{32}$. In addition, such parents may be less involved with their children and they cannot create a positive emotional atmosphere for them ${ }^{13}$.

Self-efficacy. Parents with higher self-efficacy are endowed with more self-confidence in order to achieve effective parenting skills and competence and they are also likely to have more success with positive parenting. Parental self-efficacy may affect parenting satisfaction and such an impact on coping ability can be positive. These parents may proactively make efforts in problematic situations, such as lack of social support or presence of economic problems, to reduce the negative effects of these problems on their children. In contrast, parents with lower levels of self-efficacy may not be able to adopt positive parenting strategies ${ }^{26}$.

Parenting stress. One of the factors associated with parents' characteristics is parenting stress. Parenting stress arises when parenting demands exceed the actual resources available to parents that permit them to succeed in parenting. Accordingly, parents with higher parenting stress are more rejectionists and less protective ${ }^{33}$. Greater parenting stress tends to use more punishment and less affection toward children ${ }^{34}$. Stresses affecting parenting also include child-rearing stress as well as a sense of being restrained due to the presence of children ${ }^{35}$. It has been also observed that parents with parenting stress adopt authoritarian parenting styles ${ }^{34}$. Parenting stress can similarly give parents anxiety and emotional distress and cause irritability and hostile behaviors by creating negative feelings. These parents may easily react with psychological aggression and physical punishment in the case of misbehavior by children $^{34}$.

Perfectionism. Perfectionism is a parental characteristic and also a personality trait. Accordingly, perfectionist parents try to be perfect and unflawed. They are extremely critical of themselves and their behaviors. These parents similarly consider wishes and goals they could not reach for themselves for their own children and apply their own standards to them ${ }^{36}$. Moreover, these parents may show their love to their children when children act in accordance with parents expectations. In order to maintain their self-esteem, they also put more pressure on their children to avoid failures, characterizing authoritarian parenting styles. Furthermore, perfectionist parents have high expectations of their children and these parental characteristics can result in authoritative parenting styles if they are responsive to their children $^{37}$.

Personality traits. Parental personality traits are among the most important factors influencing parenting styles ${ }^{38,39}$. According to the existing literature, the personality traits of extraversion, conscientiousness, agreeableness, and openness to experience can be accompanied by greater intimacy in parenting styles s $^{83,40}$ and a neurotic personality trait can be seen in less intimate parents. Giving a smaller amount of autonomy to children is also related to authoritarian parenting styles ${ }^{8,41,42}$. Parents with agreeable personality traits, due to their ability to obtain more social support and avoid social conflicts, generally are less likely to develop depression ${ }^{43,44}$. Agreeable parents also try to have flexible and child-centered parenting. Parents who are open to new experiences have emotionally stable personality traits and enjoy new experiences using their imagination and participate in a wide range of mental and experiential endeavors; therefore, this personality trait may be associated with positive parenting since having a child is a new experience ${ }^{44}$. As well, parents who are conscientiousness are disciplined and they are individuals with good parenting roles. Their children also accept them as an appropriate model $^{45}$. Moreover, extraverted individuals have positive emotional states and feel good about themselves and the world; and ultimately neuroticpsychotic parents have much more adverse and negative emotions $^{44,46}$.

Childhood trauma. The history of physical, sexual, or emotional abuse among parents in their childhood is considered as a risk factor leading to negative parenting styles ${ }^{27,47}$.

In this respect, perceived childhood maltreatment towards parents can have an effect on creating interpersonal problems including interactions with their own children. It is also a risk factor for subsequent emotional defects, which can result in a series of interpersonal difficulties such as distrust, uncertainty, and avoidance of intimate relationships. Also, there is a relationship between physical and emotional abuse in childhood and adverse outcomes for parents such as less parenting competence, more parenting stress, reduced use of effective parenting styles, parental hostility, use of physical punishment, and neglect towards children. In other words, a history of maltreatment can create a lasting environment during the development of children that can last until adulthood. Moreover, it has been observed that mothers with sexual abuse history in childhood may suffer from greater parenting stress, which can lead to diminished empathy with their own children ${ }^{27,48}$.

Marital satisfaction. Among the parental characteristics contributing to parenting styles is marital satisfaction ${ }^{49}$. In this respect, parents with satisfactory marital relationships may have positive behaviors with their children. Conversely, when 
parents are dissatisfied with marital relationships, negative emotions and behaviors can be transferred through parent-child interactions ${ }^{24}$. Marital conflict as a stressor can affect couples and increase their anger. Consequently, this anger can spread to children and decrease affection towards them ${ }^{15,50}$. It has been argued that marital maladjustment can lead to an increase in instability in socio-emotional domains in families resulting in ineffective and inconsistent parenting practices by parents ${ }^{51}$.

Parents' attachment style. Parental characteristics including their attachment style and family conditions in the past such as stress or supportive relationships in their immediate family can determine their parenting styles ${ }^{52,53}$. People with secure attachment styles towards their own parents consider their relationships, whether positive or negative, clear, consistent and coherent. These parents have more intimate parenting style and they are responsive to their children ${ }^{53}$. However, parents with insecure or anxious attachment in their childhood can have pervasive anger as well as lower intimacy and participation in their current relationships with their children ${ }^{53,54}$. These problems can have long-term consequences in mental health and interpersonal relationships in terms of parenting ${ }^{12}$ or some parents showing more anger towards their own parents may make special efforts to create positive relationships with their own children ${ }^{53}$.

Perceived parenting style. Individuals that have loving and responsive childhood with no severe restrictions on them are endowed with healthy socio-emotional development; they also have high self-esteem and internalized control ${ }^{55}$. As the result of emotional security, behavioral independence and social competence created in them can lead to the formation of a healthy personality and personal maturity and these people can rely more on others. Eventually, these individuals have active interactions as well as more intimacy and acceptance towards their children in the future and ultimately adopt a positive parenting style $^{8}$. In contrast, there are parents with harsh parenting during their own childhood who may treat their children strictly and believe in using more physical punishment for their children as their parents believed ${ }^{56,57}$.

Substance abuse. Substance abuse is considered as a factor affecting parenting ${ }^{14}$. Substance abuse is also recognized as a risk factor for maltreatment of children and may cause the use of violence ${ }^{47}$. Marital problems as well as psychological disorders of substance-abusing individuals are related to poor parenting ${ }^{14}$.

\section{Psychological factors relating to children}

Developmental and mental disabilities. Illnesses and disabilities of children can cause emotional distress in parents, which may lead to psychopathology, such as more anxiety, in both parents. This mental disorder can also result in negative and inappropriate parenting styles ${ }^{58}$. For example, children with disabilities such as Down's syndrome may have more behavioral problems than children without this disability, and their parents overprotect them which can lead to improper parenting. On the other hand, the siblings of these children may be cared for and controlled less than children that have no disability ${ }^{59}$. When parents cannot deal with emotional difficulties and control child temperament because of too much stress, they cannot have positive parenting styles, especially the ability to respond appropriately using a suitable approach towards their children ${ }^{58}$. Although it is demonstrated that if parents perceive the cause of their children's difficult emotional temperaments, it is possible that earning necessary skills to address these problems can reduce stress in parents and create a more positive parenting style ${ }^{58}$.

Child temperament. Child temperament such as negative emotions, maladjustment, and anger can make it difficult to care for children. It can also undermine parents' performance particularly in childhood and their behavior may become more hostile lacking love and affection ${ }^{26,60}$. Parents of children with a difficult temperament also have higher parenting stress and psychological problems, such as feeling negative about their parenting. Some characteristics seen in children, such as hyperactivity and inability to establish suitable social relationships, are similarly considered among their temperament characteristics and can have an adverse effect on parent-child relationships ${ }^{61}$. In addition, shyness is among the characteristics associated with child temperament. Thus, children with behavioral inhibition and social fearfulness are restrained and their tolerance threshold is different ${ }^{62}$. Thus, parents show more intimate behaviors towards children who have more social interactions and they are more likely to adopt much more authoritative parenting styles $^{31}$. Finally, parents with children with higher emotional intelligence can establish a better relationship with them and they may also adopt positive parenting styles ${ }^{63}$.

Anxiety. Anxiety disorder in children may lead to the adoption of a negative parenting style, such as more control. For example, a study revealed that parenting was significantly correlated with children's anxiety disorder. Such a disorder, regardless of the level of anxiety in parents, is associated with a less intimate relationship with children. Moreover, children's anxiety also causes mothers to have overprotection for their own children ${ }^{16,30}$. As well, parents having children affected with anxiety disorder may give them less independence and show not as much of acceptance and love to them ${ }^{14}$.

\section{Discussion}

This systematic review was an attempt to examine a range of psychological factors related to parenting styles to offer a useful collection that considers parent-child characteristics. The results of this study showed that studies that identify effective psychological factors for parenting styles were related. Consequently, increased self-efficacy and reduced parenting stress as well as lower depression and anxiety in parents could lead to the adoption of more appropriate strategies ${ }^{12,24,26,34}$. Moreover, dimensions of perfectionism in parents and parental personality traits could effect parenting styles ${ }^{37,39,40}$. The range of parents' psychological disturbances such as depression and anxiety could also affect parental dysfunction, leading to child maltreatment; and consequently parents' psychopathology could increase the likelihood of inappropriate and ineffective parenting ${ }^{14,24}$. 
Parenting is also influenced by the characteristics of parents' personality traits $^{40}$. These characteristics are created in the process of parents' growth and development ${ }^{8}$. Therefore, parents with greater agreeableness, extraversion, who are conscientiousness and open to new experiences, with lower neuroticism, are more intimate, organized, and stable and they are also more responsive to their children ${ }^{40,41}$.

The history of parental evolution and the way parents have interacted with their own parents can also influence how they behave with their children in the future ${ }^{56}$. If parents have been mentally disturbed in these previous relationships, their parenting ability can be adversely affected ${ }^{27,48}$. Parents experiencing love in their childhood and having a secure attachment to their parents can show more positive parenting in adulthood for their children, while insecure attachments may be a risk factor for future parenting and reduce their positive parenting capacities ${ }^{53,54}$. Studies have also shown how childhood trauma as well as physical, sexual, and emotional abuse during childhood can shape parenting styles in the future. The experience of these injuries can similarly lead to emotional and social impairment and disturb parent-child interactions, and consequently make parents adopt negative parenting styles ${ }^{27,48}$.

The results of this study indicated that parents having satisfactory and supportive marital relationships were more sensitive and responsive to their child's needs ${ }^{34,49}$. In addition, psychological factors such as depression and parenting stress can affect other types of family relationships, such as marital and parent-child relationships ${ }^{24,34,35}$. Moreover, substance abuse was recognized as a risk factor for exercising violence against children $^{47}$.

In general, the findings suggested that children's psychological characteristics such as developmental and mental disabilities, temperament, social fearfulness and shyness, attachment, anxiety, and emotional intelligence should be considered in determining the factors contributing to parenting styles. These factors may also bring about psychological problems in parents such as negative feelings about parenting or even lead to challenging behaviors in children or mental health problems in children or parents, which in turn can have an effect on parenting styles $^{30,59,63}$.

In conclusion, considering these multiple psychological factors influencing parenting styles, we recommended including parent-child psychological status assessment in family health programs in order to identify the needs for health-oriented care and take steps towards the development of parenting skills among parents.

\section{Limitations}

Although this study examined the psychological factors contributing to parenting styles, the impact of couples' psychological characteristics on each other's parenting styles was not elucidated. Therefore, future research can shed light on the psychological characteristics of couples interacting with each other as well as the effects on their parenting styles. Despite these limitations it seems the result of this study can be used in the development and implementation of family health intervention programs. Also clinicians, psychologists, psychiatrists, and counselors may consider the psychological factors affecting parenting styles reported in this review for further interventions; the assessment of parent-child mental health status, as well as positive parenting education and in this way help with positive parent-child interactions.

\section{Data availability}

All data underlying the results are available as part of the article and no additional source data are required.

\section{Competing interests}

No competing interests were disclosed.

\section{Grant information}

Student Research Committee of Mazandaran University of Medical Sciences for their financial support of this project (code number, 2952).

The funders had no role in study design, data collection and analysis, decision to publish, or preparation of the manuscript.

\section{Supplementary material}

Supplementary File 1: PRISMA checklist.

Click here to access the data.

Supplementary File 2: Quality assessment of all articles. 
1. Smetana JG: Parenting styles and beliefs about parental authority. New Directions for Child Adol Develop. 1994; 1994(66): 21-36. Publisher Full Text

2. Haghighi M, Khalilzadeh R: A Survey on relationship between marital satisfaction and parenting styles. J Urmia Nurs Midwifery. 2011; 10(1): 21-26. Reference Source

3. Gholami F, Ghanizadeh A, Dehbozorgi G: A Survey of marital satisfaction, parenting styles and parent attachment styles in parents of preschool and school children with nail biting, compared with a control group. IJHSS. 2014; 4(14): 200-206.

Reference Source

4. Smokowski PR, Bacallao ML, Cotter KL, et al:: The effects of positive and negative parenting practices on adolescent mental health outcomes in a multicultural sample of rural youth. Child Psychiatry Hum Dev. 2015; 46(3): 333-45.

PubMed Abstract | Publisher Full Text

5. Milevsky A, Schlechter M, Netter S, et al:: Maternal and paternal parenting styles in adolescents: Associations with self-esteem, depression and lifesatisfaction. J Child Fam Stud. 2007; 16(1): 39-47.

Publisher Full Text

6. Maddahi ME, Javidi N, Samadzadeh M, et al:: The Study of relationship between parenting styles and personality dimensions in a sample of college students. Indian J Sci Technol. 2012; 5(9): 3332-3336.

Reference Source

7. Tan TX, Camras LA, Deng H, et al.: Family stress, parenting styles, and behavioral adjustment in preschool-age adopted Chinese girls. Early Child Res Q. 2012; 27(1): 128-136.

Publisher Full Text

8. Belsky J: The determinants of parenting: a process model. Child Dev. 1984; 55(1): 83-96.

PubMed Abstract | Publisher Full Text

9. Onder A, Gulay $\mathrm{H}$ : Reliability and validity of parenting styles and dimensions questionnaire. Procedia Soc Behav Sci. 2009; 1(1): 508-514. Publisher Full Text

10. Stith SM, Liu T, Davies LC, et al.: Risk factors in child maltreatment: A metaanalytic review of the literature. Aggress Violent Behav. 2009; 14(1): 13-29. Publisher Full Text

11. Lovejoy MC, Graczyk PA, O'Hare E, et al:: Maternal depression and parenting behavior: a meta-analytic review. Clin Psychol Rev. 2000; 20(5): 561-592. PubMed Abstract | Publisher Full Text

12. Christian VA: Factors that increase successful parenting skills in adult survivors of childhood trauma, neglect, and abuse: a systematic review. 2017. Reference Source

13. Oyserman D, Mowbray CT, Meares PA, et al:: Parenting among mothers with a serious mental illness. Am J Orthopsychiatry. 2000; 70(3): 296-315. PubMed Abstract | Publisher Full Text

14. Berg-Nielsen TS, Vikan A, Dahl AA: Parenting related to child and parental psychopathology: a descriptive review of the literature. Clin Child Psychol Psychiatry. 2002; 7(4): 529-552. Publisher Full Text

15. Troxel WM, Matthews KA: What are the costs of marital conflict and dissolution to children's physical health? Clin Child Fam Psychol Rev. 2004; 7(1): 29-57. PubMed Abstract | Publisher Full Text

16. van der Bruggen CO, Stams GJ, Bögels SM: Research review: the relation between child and parent anxiety and parental control: a meta-analytic review. J Child Psychol Psychiatry. 2008; 49(12): 1257-1269.

PubMed Abstract | Publisher Full Text

17. Liberati A, Altman DG, Tetzlaff $J$, et al:: The PRISMA statement for reporting systematic reviews and meta-analyses of studies that evaluate health care interventions: explanation and elaboration. J Clin Epidemiol. 2009; 62(10): e1-34. PubMed Abstract | Publisher Full Text

18. Sackett D, Richardson WS, Rosenburg W, et al.: How to practice and teach evidence based medicine. 2nd ed Churchill Livingstone. 1997.

19. Hulley SB, Cummings SR, Browner WS, et al.: Designing clinical research. 3rd ed Lippincott Williams and Wilkins. 2007.

Reference Source

20. Wells GA, Shea B, O'Connell D, et al:: The Newcastle-Ottawa Scale (NOS) for assessing the quality of nonrandomized studies in meta-analysis. 2011. Reference Source

21. McPheeters ML, Kripalini S, Peterson NB, et al:: Quality Improvement Interventions To Address Health Disparities. Evidence Report/ technology Assessment. Rockville (MD): Agency for Healthcare Research and Quality (US) 2012 . Reference Source

22. Gariepy G, Nitka D, Schmitz N: The association between obesity and anxiety disorders in the population: a systematic review and meta-analysis. Int $J$ Obes (Lond). 2010; 34(3): 407-19. PubMed Abstract | Publisher Full Text

23. Baker PR, Dobbins $M$, Soares $\mathrm{J}$, et al:: Public health interventions for increasing physical activity in children, adolescents and adults: an overview of systematic reviews. Cochrane Database Syst Rev. 2015; Art. No.: CD011454. Publisher Full Text

24. Chang L, Lansford JE, Schwartz D, et al.: Marital quality, maternal depressed affect, harsh parenting, and child externalising in hong kong Chinese families. Int J Behav Dev. 2004; 28(4): 311-318.

Publisher Full Text

25. Adam EK, Gunnar MR, Tanaka A: Adult attachment, parent emotion, and observed parenting behavior: mediator and moderator models. Child Dev. 2004; 75(1): 110-122.

PubMed Abstract | Publisher Full Text

26. Jones TL, Prinz RJ: Potential roles of parental self-efficacy in parent and child adjustment: a review. Clin Psychol Rev. 2005; 25(3): 341-363. PublMed Abstract | Publisher Full Text

27. Banyard VL, Williams LM, Siegel JA: The impact of complex trauma and depression on parenting: an exploration of mediating risk and protective factors. Child Maltreat. 2003; 8(4): 334-349.

PubMed Abstract | Publisher Full Text

28. Webster-Stratton C, Hammond M: Maternal depression and its relationship to life stress, perceptions of child behavior problems, parenting behaviors, and child conduct problems. J Abnorm Child Psychol. 1988; 16(3): 299-315. PubMed Abstract | Publisher Full Text

29. Levendosky AA, Graham-Bermann SA: Parenting in battered women: The effects of domestic violence on women and their children. JOFV. 2001; 16(2): 171-192. Publisher Full Text

30. Moore PS, Whaley SE, Sigman M: Interactions between mothers and children: impacts of maternal and child anxiety. J Abnorm Psychol. 2004; 113(3): 471-476. PubMed Abstract | Publisher Full Text

31. Chen F-M, Luster T: Factors related to parenting practices in Taiwan. Early Child Educ J. 2002; 172(5): 413-430 Publisher Full Text

32. Goodman SH, Brumley HE: Schizophrenic and depressed mothers: Relational deficits in parenting. Dev Psychol. 1990; 26(1): 31-39. Publisher Full Text

33. Alavi Z, Afrooz GA, Ghasemzade S: Explore The Relationship Between Stress And Parenting Styles Of Mothers Of Children With Satisfaction Parity Aggressive. MEJDS. 2015; 5(11): 230-41.

Reference Source

34. Li L, Wang M: Parenting stress and harsh discipline in China: The moderating roles of marital satisfaction and parent gender. Child Abuse Negl. 2015; 43: $73-82$.

PubMed Abstract | Publisher Full Text

35. Ponnet K, Mortelmans D, Wouters $\mathrm{E}$, et al.: Parenting stress and marital relationship as determinants of mothers' and fathers' parenting. Pers Relatsh. 2013: 20(2): 259-276. Publisher Full Text

36. Salibi J, Ahamadi AS: The Relationship between childrearing styles and perfectionism in mothers and emotional and social adjustment of their eighthgrade girls. Pazhuheshname-Ye Zanan (Women's Studies). 2013; 4(7): 139-162.

37. Besharat MA, Azizi K, Hoseini SA: The relationship between parental perfectionism and parenting styles. Quarter J Res Edu Sys. 2010; 4(8): 9-29. Reference Source

38. Kitamura T, Shikai N, Uji M, et al.: Intergenerational transmission of parenting style and personality: direct influence or mediation? J Child Fam Stud. 2009; 18(5): 541-556.

Publisher Full Text

39. Huver RM, Otten R, de Vries $\mathrm{H}$, et al.: Personality and parenting style in parents of adolescents. J Adolesc. 2010; 33(3): 395-402 PubMed Abstract | Publisher Full Text

40. Aluja A, del Barrio V, García LF: Personality, social values, and marita satisfaction as predictors of parents rearing styles. Int $J$ Clin Health Psychol. 2007; 7(3): 725-737. Reference Source

41. Dickson E, Agyemang CB, Afful J: Parental personality and parenting style. A Ghanaian Perspective. IISTE. 2014; 4(5): 116-128. Reference Source

42. Prinzie P, Stams GJ, Deković M, et al.: The relations between parents' Big Five personality factors and parenting: a meta-analytic review. J Pers Soc Psychol. 2009; 97(2): 351-362.

PubMed Abstract | Publisher Full Text

43. Maddahi M, Samadzadeh M: Parenting styles and personality traits. Thinking \& Behavior. 2011; 6(21): 17-24.

44. Browne DT, Meunier JC, O'connor TG, et al:: The role of parental personality traits in differential parenting. J Fam Psychl. 2012; 26(4): 542-553. PubMed Abstract | Publisher Full Text

45. Rezayi Aval M, Tahmasebi S, Maleki B: The Effects Of Five Dimensions Of Personality And Mental Health Of Parents On Parenting Styles. IJHCS. 2016; (Special Issue): 314-27. Reference Source

46. Edobor OJ, Ekechukwu R: Parenting Styles And Personality Traits Among Senior Secondary Students In Rivers State Nigeria, West African. BJPR. 2015; 
3(4): 9-18.

Reference Source

47. Frias-Armenta M, McCloskey LA: Determinants of harsh parenting in mexico. J Abnorm Child Psychol. 1998; 26(2): 129-39.

PubMed Abstract | Publisher Full Text

48. Bailey HN, DeOliveira CA, Wolfe VV, et al.: The impact of childhood maltreatment history on parenting: a comparison of maltreatment types and assessment methods. Child Abuse Negl. 2012; 36(3): 236-246. PubMed Abstract | Publisher Full Text

49. Awuah $\mathrm{D}$ : The Relationship between parenting style, attachment style and marital among married men and women. university of ghana; 2013. Reference Source

50. Osborne LN, Fincham FD: Marital conflict, parent-child relationships, and child adjustment: does gender matter? Merrill-Palmer Quarter. 1996; 42(1): $48-75$. Reference Source

51. Tavassolie T, Dudding S, Madigan AL, et al.: Differences in perceived parenting style between mothers and fathers: implications for child outcomes and marital conflict. J Child Fam Stud. 2016; 25(6): 2055-2068. Publisher Full Text

52. Kotchick BA, Forehand R: Putting parenting in perspective: A discussion of the contextual factors that shape parenting practices. J Child Fam Stud. 2002; 11(3): 255-269. Publisher Full Text

53. Cowan PA, Cowan CP, Cohn DA, et al.: Parents' attachment histories and children's externalizing and internalizing behaviors: exploring family systems models of linkage. J Consult Clin Psychol. 1996; 64(1): 53-63. PubMed Abstract | Publisher Full Text

54. Booth CL: Predicting social adjustment in middle childhood: the role of preschool attachment security and maternal style. Social Develop. 1994; 3(3): 189-204.

Publisher Full Text
55. Zakeri H, Karimpour M: Parenting styles and self-esteem. Procedia Soc Behav Sci. 2011; 29: 758-61.

Publisher Full Text

56. Simons RL, Whitbeck LB, Conger RD, et al:: Intergenerational transmission of harsh parenting. Dev Psychol. 1991; 27(1): 159-171.

Publisher Full Text

57. Kendler KS, Sham PC, MacLean CJ: The determinants of parenting: an epidemiological, multi-informant, retrospective study. Psychol Med. 1997; 27(3): 549-563.

PubMed Abstract

58. Nam S, Chun J: Influencing factors on mothers' parenting style of young children at risk for developmental delay in South Korea: The mediating effects of parenting stress. Child Youth Serv Rev. 2014; 36: 81-9. Publisher Full Text

59. Gau SS, Chiu YN, Soong WT, et al:: Parental characteristics, parenting style, and behavioral problems among chinese children with Down syndrome, their siblings and controls in Taiwan. J Formos Med Assoc. 2008; 107(9): 693-703. PubMed Abstract

60. Yu JJ, Gamble WC: Pathways of influence: marital relationships and their association with parenting styles and sibling relationship quality. $J$ Child Fam Stud. 2008; 17(6): 757-778. Publisher Full Text

61. McBride BA, Schoppe SJ, Rane TR: Child characteristics, parenting stress, and parental involvement: Fathers versus mothers. J Marriage Fam. 2002; 64(4): 998-1011.

Publisher Full Text

62. Rubin $\mathrm{KH}$, Nelson LJ, Hastings $\mathrm{P}$ : The transaction between parents' perceptions of their children's shyness and their parenting styles. Int J Behav Dev. 1999; 23(4): 937-957. Publisher Full Text

63. Abdollahi A, Talib MA, Motalebi SA: Perceived parenting styles and emotional intelligence among Iranian boy students. AJSS H. 2013; 2(3): 460-7. Reference Source 


\section{Open Peer Review}

\section{Current Peer Review Status: ? $\mathrm{X}$}

\section{Version 1}

Reviewer Report 04 March 2019

https://doi.org/10.5256/f1000research.16306.r44614

(C) 2019 Fan W. This is an open access peer review report distributed under the terms of the Creative Commons Attribution License, which permits unrestricted use, distribution, and reproduction in any medium, provided the original work is properly cited.

\section{Weiqiao Fan}

Research Institute of International and Comparative Education, Department of Psychology, Shanghai Normal University, Shanghai, China

The topic of the manuscript is extremely important and interesting. The manuscript provided a summary for factors of parenting styles. However, the manuscript did not establish a clear research gap and a clear research purpose. The author(s) did not provide logic rationales for the research. What's more, there is not a logical introduction to deduce the research questions. In other words, more attention should be paid for the major issues. Therefore, I do not think the manuscript should be indexed.

There are some specific comments to the manuscripts, which may help the author(s) to improve the work.

1. There are many models for parenting styles in the literature. Different model may relate with different factors. However, the author(s) did not touch this issue. Or rather, this is not a logical introduction to this paper. Accordingly, this manuscript cannot have a significant contribution in theory or practice.

2. The definition of "parenting styles" in the first sentence is not liberal. And it cannot reflect the main meaning of parenting style in literature.

3. In Introduction section, the concepts and theory are not clear. Authors should clearly describe parenting styles, the factors and models. Meanwhile, the research questions and significance of the study should also be clearly stated.

4. I cannot see a thorough review for "review of parenting style" in literature. This should be the foundation of the current manuscript.

5. In Method section, each subsection is well defined with clear headings, but in "search strategy" section, I find it difficult to understand why the retrieved articles were based on medical subject headings.

6. After results, the author(s) should explain the results and compare the results to those previous review works in the literature, rather than simply repeating the results.

7. The author(s) should also add some sections as contribution and implication section to discuss the contributions of the manuscript in theory at least.

8. The authors should reorganize the paragraphs based on the importance of factors or some 
other logics.

9. The writing and grammar should be improved, and the manuscript is limited by the lack of clarity in the writing.

Are the rationale for, and objectives of, the Systematic Review clearly stated? Partly

Are sufficient details of the methods and analysis provided to allow replication by others? Yes

Is the statistical analysis and its interpretation appropriate?

I cannot comment. A qualified statistician is required.

Are the conclusions drawn adequately supported by the results presented in the review? Partly

Competing Interests: No competing interests were disclosed.

Reviewer Expertise: personality theory and assessment; career assessment

I confirm that I have read this submission and believe that I have an appropriate level of expertise to state that I do not consider it to be of an acceptable scientific standard, for reasons outlined above.

Author Response 30 Mar 2019

Zohreh Shahhosseini, Mazandaran University of Medical Sciences, Sari, Iran

The topic of the manuscript is extremely important and interesting. The manuscript provided a summary for factors of parenting styles. However, the manuscript did not establish a clear research gap and a clear research purpose. The author(s) did not provide logic rationales for the research. What's more, there is not a logical introduction to deduce the research questions. In other words, more attention should be paid for the major issues. Therefore, I do not think the manuscript should be indexed.

There are some specific comments to the manuscripts, which may help the author(s) to improve the work.

There are many models for parenting styles in the literature. Different model may relate with different factors. However, the author(s) did not touch this issue. Or rather, this is not a logical introduction to this paper. Accordingly, this manuscript cannot have a significant contribution in theory or practice.

Response: Introduction section was revised in page 2, paragraph 1, line 1-15

The definition of "parenting styles" in the first sentence is not liberal. And it cannot reflect the main meaning of parenting style in literature.

Response: Introduction section was revised in page 2, paragraph 1, line 1-3

In Introduction section, the concepts and theory are not clear. Authors should clearly describe parenting styles, the factors and models. Meanwhile, the research questions 
and significance of the study should also be clearly stated.

Response: Introduction section was revised in page 2, paragraph 1, line 1-15 and in page 2, paragraph 2, line 4-6

I cannot see a thorough review for "review of parenting style" in literature. This should be the foundation of the current manuscript.

Response: Introduction section was revised in page 2, paragraph 1, line 3-15

In Method section, each subsection is well defined with clear headings, but in "search strategy" section, I find it difficult to understand why the retrieved articles were based on medical subject headings.

Medical Subject Headings is a comprehensive controlled vocabulary for the purpose of indexing journal articles and books in the life sciences; it serves as a thesaurus that facilitates searching.

After results, the author(s) should explain the results and compare the results to those previous review works in the literature, rather than simply repeating the results.

Response: Discussion section was revised in page 11, paragraph 1, line 1-5 and in, paragraph 2, line 8-10 and page 12, paragraph 1, line 7- 11

The author(s) should also add some sections as contribution and implication section to discuss the contributions of the manuscript in theory at least.

Response: Implication section was add in page 12, paragraph 3, line 1-2

The authors should reorganize the paragraphs based on the importance of factors or some other logics.

Response: Introduction section was revised in page 5-9

The writing and grammar should be improved, and the manuscript is limited by the lack of clarity in the writing.

Response: It was revised.

Competing Interests: No competing interests were disclosed.

Reviewer Report 02 August 2018

https://doi.org/10.5256/f1000research.16306.r35469

(c) 2018 Zamanian M. This is an open access peer review report distributed under the terms of the Creative Commons Attribution License, which permits unrestricted use, distribution, and reproduction in any medium, provided the original work is properly cited.

\section{Maryam Zamanian}

Department of Epidemiology, School of Health, Arak University of Medical Sciences, Arak, Iran

In my view this paper is valuable and suitable for indexing after doing the comments

The methodological quality of the study is fair but I think it should be evaluated by an expert of Psychiatry in terms of psychology concepts, classifications of Psychological 
characteristics and other issues.

Maybe the category of "Psychological factors relating to children" is not needed.

The section of "These factors can differently contribute to parenting style. Thus," is unnecessary in abstract section.

The introduction section of manuscript needs more clarification on parenting styles and factors contributing to raising children and the importance of .

The discussion section just has repeated the results, while it should compare the results with those from other studies, and provide possible reasons to explain the results with additional clarifications. Moreover it should be written in order of most to least important. The conclusions section is just one recommendation, not the real conclusion. It should be written more powerful and as a real conclusion of research which re-states the main points in a new concise way.

It should be worked to improve the quality of the English grammar throughout the manuscript.

Are the rationale for, and objectives of, the Systematic Review clearly stated?

Yes

Are sufficient details of the methods and analysis provided to allow replication by others? Yes

Is the statistical analysis and its interpretation appropriate?

Not applicable

Are the conclusions drawn adequately supported by the results presented in the review? Partly

Competing Interests: No competing interests were disclosed.

I confirm that I have read this submission and believe that I have an appropriate level of expertise to confirm that it is of an acceptable scientific standard, however I have significant reservations, as outlined above.

Author Response 30 Mar 2019

Zohreh Shahhosseini, Mazandaran University of Medical Sciences, Sari, Iran

In my view this paper is valuable and suitable for indexing after doing the comments

The methodological quality of the study is fair but I think it should be evaluated by an expert of Psychiatry in terms of psychology concepts, classifications of Psychological characteristics and other issues.

Maybe the category of "Psychological factors relating to children" is not needed.

Response: Some child psychologic factors affecting parenting styles so "Psychological factors relating to children" did not delete.

The section of "These factors can differently contribute to parenting style. Thus," is unnecessary in abstract section.

Response: Introduction section was revised in page 1, paragraph 2, line 3 
The introduction section of manuscript needs more clarification on parenting styles and factors contributing to raising children and the importance of .

Response: Introduction section was revised in page 2, paragraph 1, line 1-15 and in page 2, paragraph 2, line 4-6

The discussion section just has repeated the results, while it should compare the results with those from other studies, and provide possible reasons to explain the results with additional clarifications. Moreover it should be written in order of most to least important.

Response: The Discussion section was revised in page 11, paragraph 1, line 1-5 and in, paragraph 2, line 8-10 and page 12, paragraph 1, line 7- 11

The conclusions section is just one recommendation, not the real conclusion. It should be written more powerful and as a real conclusion of research which re-states the main points in a new concise way.

Response: The conclusions section was revised in page 12, paragraph 1, line 6-7 and in,

It should be worked to improve the quality of the English grammar throughout the manuscript.

Response: It was revised.

Competing Interests: No competing interests were disclosed.

The benefits of publishing with F1000Research:

- Your article is published within days, with no editorial bias

- You can publish traditional articles, null/negative results, case reports, data notes and more

- The peer review process is transparent and collaborative

- Your article is indexed in PubMed after passing peer review

- Dedicated customer support at every stage

For pre-submission enquiries, contact research@f1000.com 